\title{
Pancreatic rupture during childbirth treated successfully by endoscopic drainage
}

A 22-year-old woman was referred to our hospital for intensifying epigastric pain, 3 days after giving birth. The last stage of labor had been assisted by manual compression of the uterus, during which the patient had a painful, tearing sensation in the upper abdomen. Initial laboratory findings were as follows: hemoglobin $91 \mathrm{~g} / \mathrm{L}$, white blood cell count $21500 / \mu \mathrm{L}$, and amylase $567 \mathrm{IU} / \mathrm{L}$. Abdominal computed tomography (CT) revealed near-total rupture of the pancreas ( Fig. 1).

The patient underwent endoscopic retrograde cholangiopancreaticography, and a leak from the main duct of pancreas was noted ( $\bullet$ Fig. 2). The distal portion of the pancreatic duct and the rupture site were dilated using a $4 \mathrm{~mm} / 4 \mathrm{~cm}$ balloon, followed by placement of a $12 \mathrm{~cm} / 5 \mathrm{Fr}$ stent ( Fig.3). Subsequently, an ultrasoundguided drain was inserted into the upper abdomen. The patient was kept on parenteral nutrition and somatostatin therapy for 7 days. Due to presence of pleural effusion a drain was introduced into the left pleural cavity. The patient developed paralytic ileus, which was treated conservatively. At 2 days following stent placement, a follow-up abdominal CT revealed no complications ( Fig.4). The patient was discharged 12 days after admission. No complications were evident on abdominal magnetic resonance imaging at 2 months and the stent was removed after 3 months. At 6 months, secretinstimulated magnetic resonance cholangiopancreaticography revealed no pathology ( Fig.5) and the patient had fully recovered.

The most important factor determining the outcome of pancreatic injuries is ductal integrity $[1,2]$. Distal lacerations with ductal involvement, grade III according to the pancreas Organ Injury Scale [3], are traditionally treated with resection [4]. In the present patient, the diagnosis was made after 3 days. Delay is associated with increased morbidity and complication rate. However, external drainage, pancreatic stenting, and otherwise conservative treatment led to complete recovery in the present case.

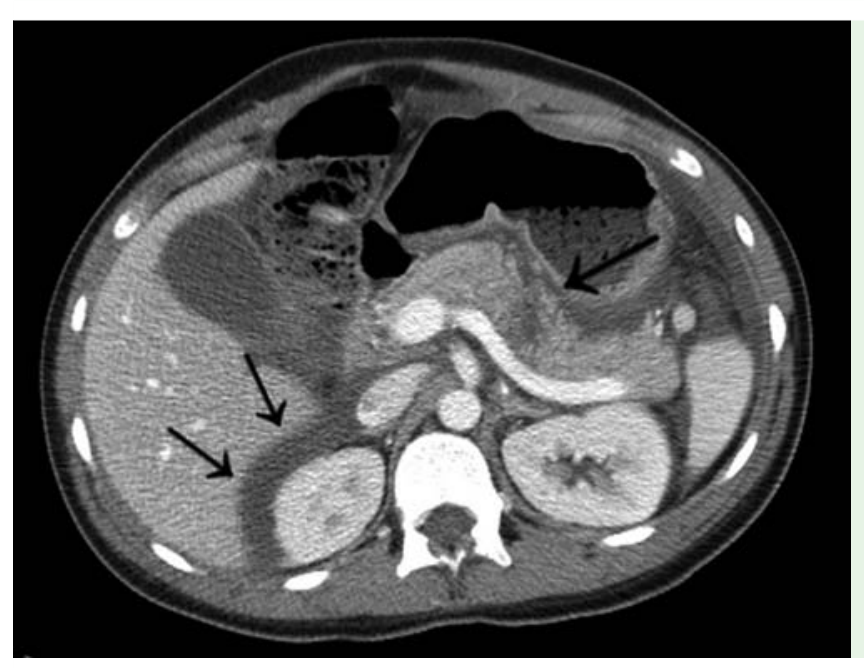

Fig. 1 Near-total rupture of the pancreas (large arrow) and free fluid in the abdominal cavity (small arrows) in a young woman a few days after giving birth.

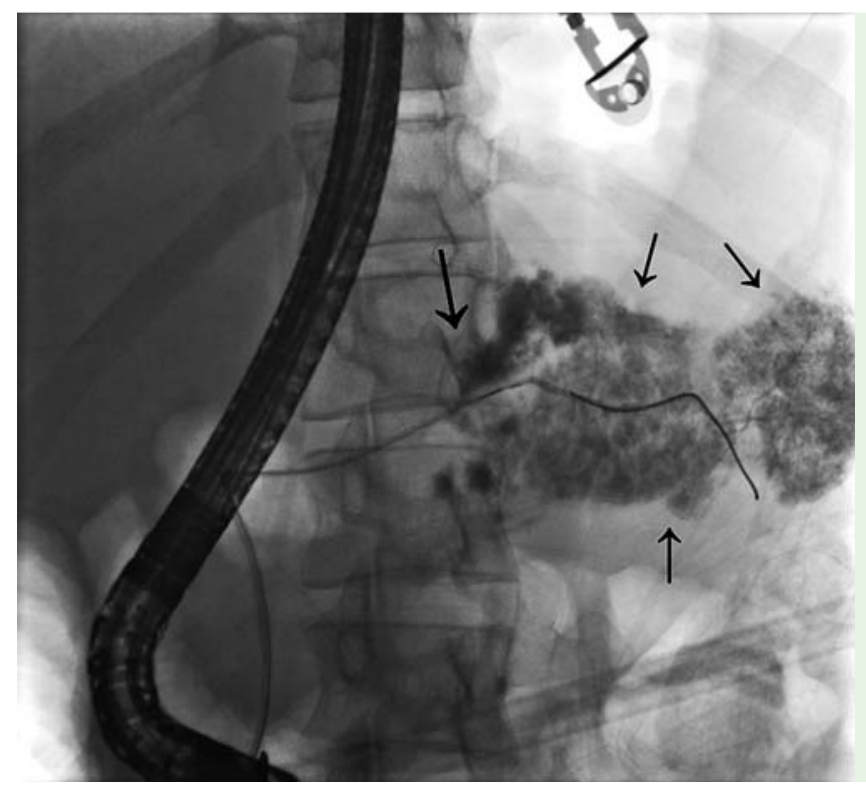

Fig. 2 The guide wire in the distal portion of the pancreas. The contrast medium had leaked from the main duct (large arrow) to the peripancreatic space (small arrows).

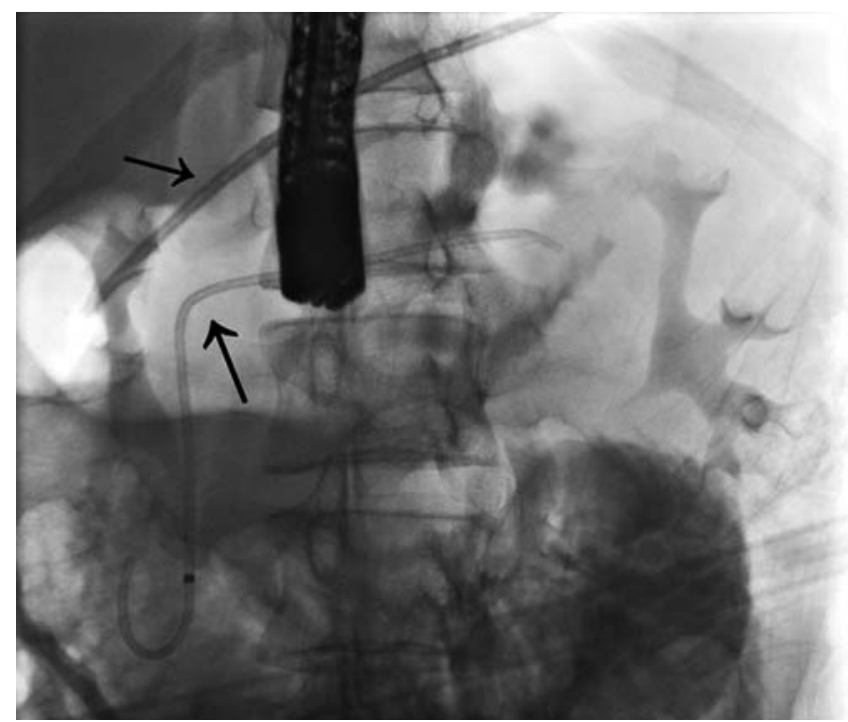

Fig. 3 The stent was successfully introduced over the rupture site (large arrow). Another stent is seen lying in the stomach after a failed attempt (small arrow). 

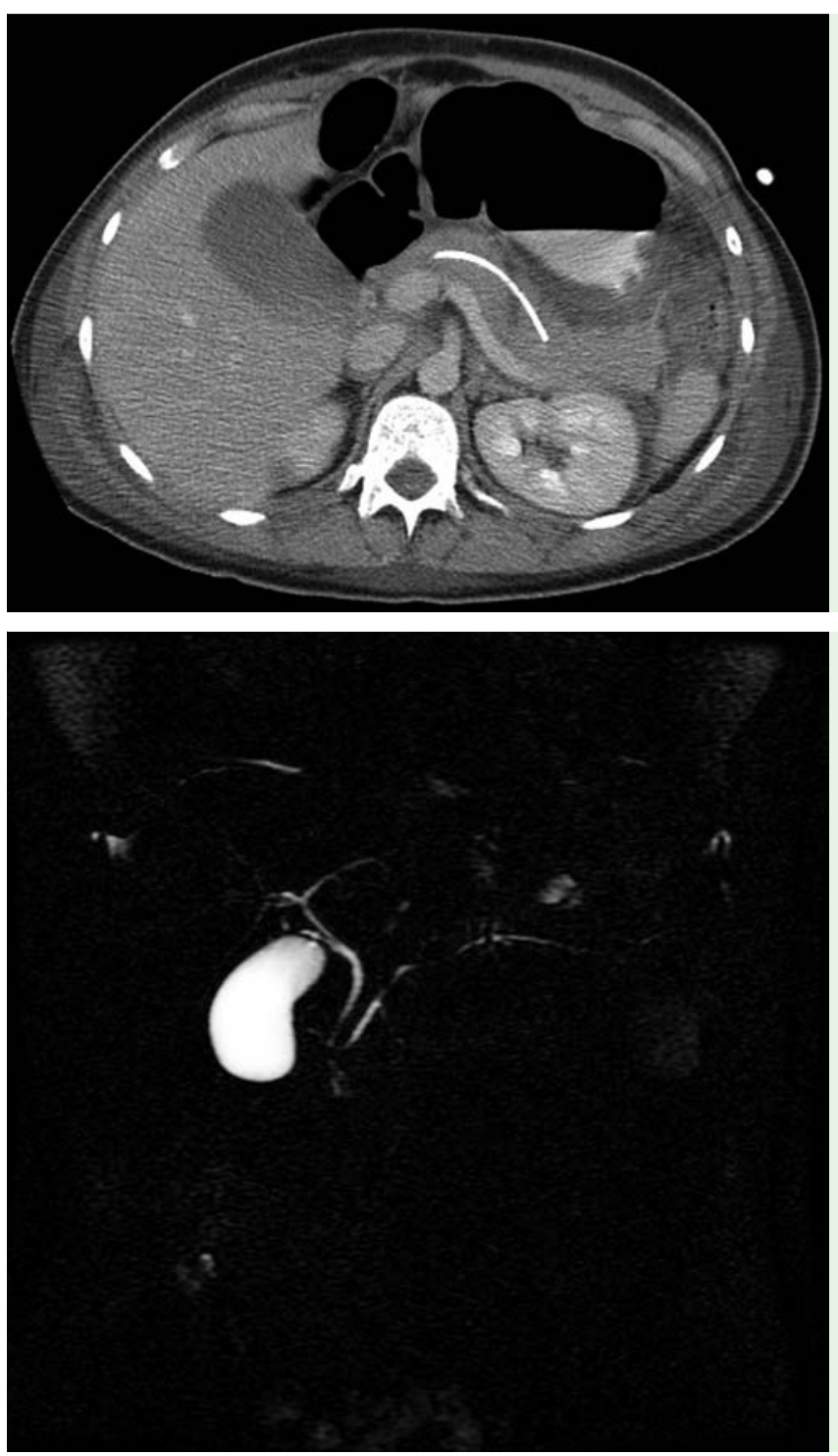

Fig. 4 Follow-up computed tomography (CT) image 2 days after the placement of the stent.

Endoscopy_UCTN_Code_CCL_1AZ_2AM

\section{Competing interests: None}

\section{J. Khan, J. Ylinen, M. Victorzon}

Department of Surgery, Vaasa Central Hospital, Vaasa, Finland

\section{References}

1 Subramanian A, Dente CJ, Feliciano DV. The management of pancreatic trauma in the modern era. Surg Clin North Am 2007; 87: 1515-1532

2 Stawicki SP, Schwab CW. Pancreatic trauma: demographics, diagnosis, and management. Am Surg 2008; 74: 1133 - 1145

Fig. 5 Magnetic resonance cholangiopancreaticography showing no ductal abnormalities or fluid collections.

3 Moore EE, Cogbill TH, Malangoni MA et al. Organ injury scaling, II: Pancreas, duodenum, small bowel, colon, and rectum. J Trauma 1990; 30: 1427-1429

4 Malgras B, Douard R, Siauve N et al. Management of left pancreatic trauma. Am Surg 2011; 77: $1-9$

\section{Bibliography}

Dol http://dx.doi.org/

$10.1055 / \mathrm{s}-0031-1291566$

Endoscopy 2012; 44: E65-E66

(c) Georg Thieme Verlag KG

Stuttgart · New York

ISSN 0013-726X

\section{Corresponding author}

\section{J. Khan}

Department of Surgery

Vaasa Central Hospital

Hietalahdenkatu 2-4

65130 Vaasa

Finland

Fax: +358-06-3231528

jahangir.khan@uta.fi 